\title{
About the role of oxygen defects in the catalytic performance of zinc oxide
}

By Sebastian Polarz, ${ }^{1 *}$ Jennifer Strunk, ${ }^{2}$ Vladislav Ischenko, ${ }^{1}$ Maurits W. E. van den Berg, ${ }^{2}$ Olaf Hinrichsen, ${ }^{2 *}$ Martin Muhler, ${ }^{2}$ Matthias Driess. ${ }^{1}$

1) Dr. S. Polarz, Dr. V. Ischenko, Prof. Dr. M. Driess; Technical University Berlin, Institute of Chemistry, Strasse des 17. Juni 135, 10623 Berlin, Germany;

E-mail: sebastian.polarz@tu-berlin.de.

2) Dipl.-Chem. J. Strunk, Dr. M. W. E. van den Berg, Prof. Dr. O. Hinrichsen, Prof. Dr. M. Muhler; Ruhr-Universität Bochum, Fakultät für Chemie, Universitaetsstr. 150, 44780

Bochum; E-mail: olaf@techem.ruhr-uni-bochum.de. 
Fig. SI1:

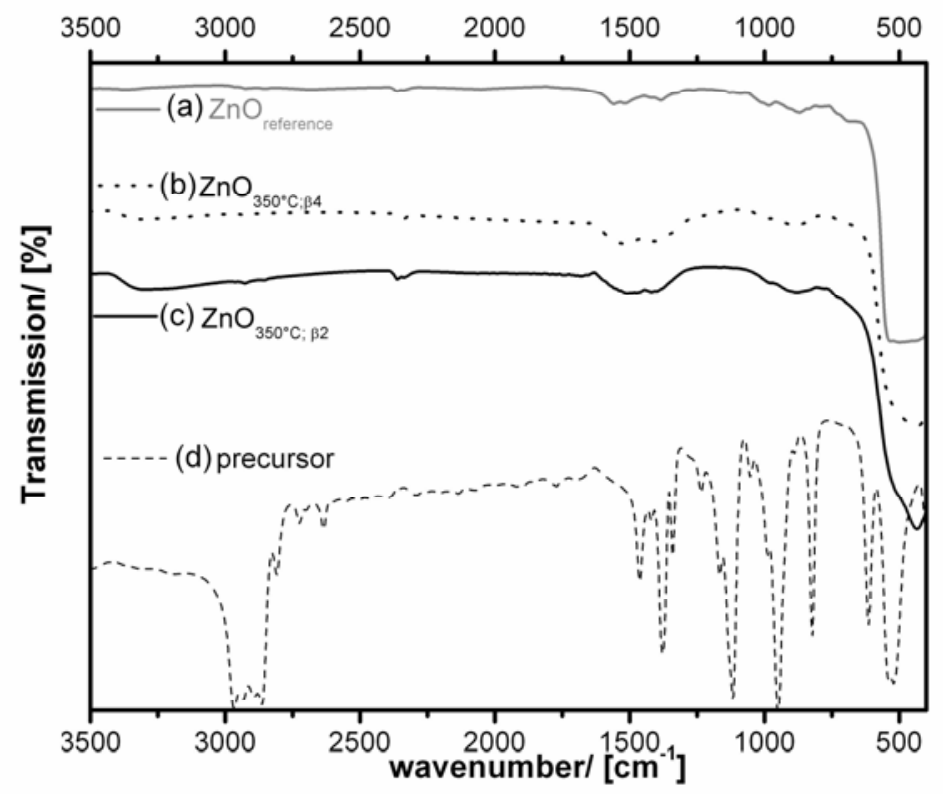

IR spectra of the precursor (d), the product after treatment at $\mathrm{T}_{\mathrm{e}}=350^{\circ} \mathrm{C}$ and $\beta_{2}=5 \mathrm{~K} / \mathrm{min}(\mathrm{c})$, the product obtained for strong non-equilibrium conditions $\beta_{4}=30 \mathrm{~K} / \mathrm{min}(\mathrm{b})$, and of the reference sample, commercial zinc oxide (a). 
SI 1: TG-MS measurement of the thermolysis of $\left[\mathrm{CH}_{3} \mathrm{ZnOCH}\left(\mathrm{CH}_{3}\right)_{2}\right]_{4}$.

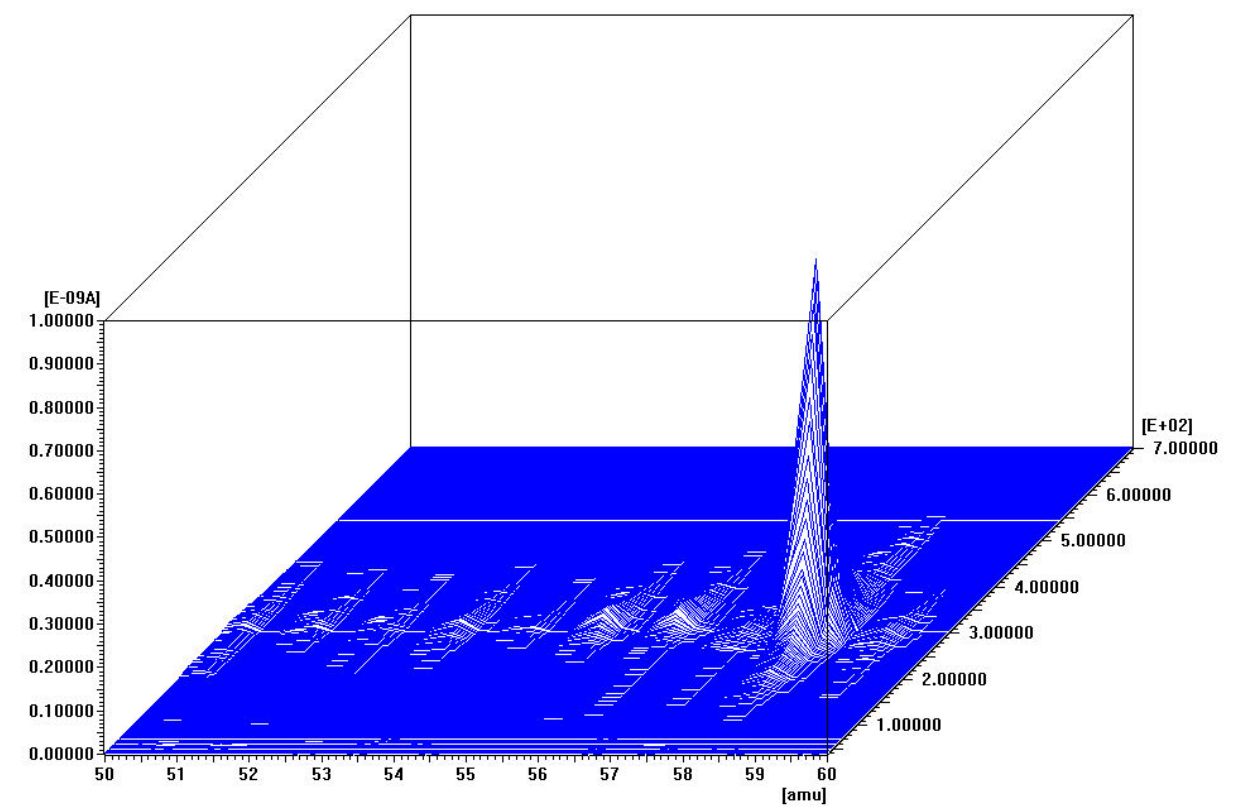

The precursor $\left[\mathrm{CH}_{3} \mathrm{ZnOCH}\left(\mathrm{CH}_{3}\right)_{2}\right]_{4}$ was decomposed under inert conditions in argon atmosphere using a thermogravimetric equipment coupled to a mass-spectrometer. Clearly, the elimination of acetone $(\mathrm{m} / \mathrm{z}=58)$ is seen. 


\section{SI2: XPS-DATA}

We were not able to distinguish sample ( $\mathrm{ZnO}) \mathrm{II}$ from a standard commercially obtained zinc oxide (Manufacturer: Alfa, 99.9995\%) by means of XPS, as differences between the samples were all within experimental error. Both samples had a $\mathrm{Zn}: \mathrm{O}$ atomic ratio of $\sim 1.0$. The $\mathrm{O} 1 \mathrm{~s}$ line was resolved into two peaks, which we assigned to structural oxygen (at $530.5 \mathrm{eV}$ ) and to surface $\mathrm{OH}$-groups (at $532.0 \mathrm{eV}) .{ }^{[\mathrm{SI} 1]}$ The Auger parameters $\left(\alpha_{Z n}^{\prime}=B E_{Z n 2 p_{3 / 2}}+K E_{Z n_{L M M}}\right)$ for both samples were identical at $2010.0 \mathrm{eV}$. Apart from adventitious carbon, no contaminations of other elements were found in the survey scans.

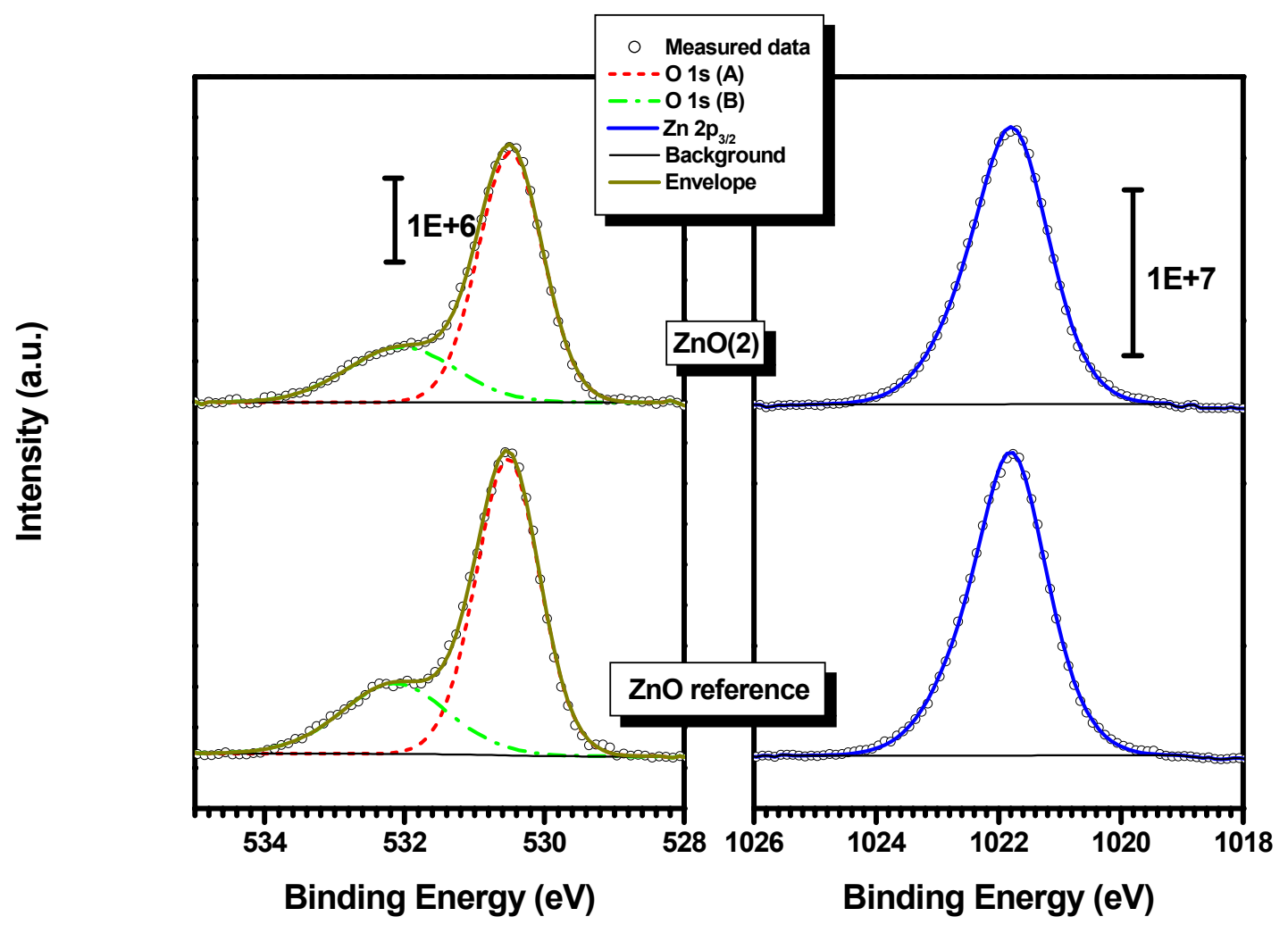

$\mathrm{O} 1 \mathrm{~s}$ line (left) and $\mathrm{Zn} 2 \mathrm{p}_{3 / 2}$ line (right) of a commercial $\mathrm{ZnO}$ reference sample (bottom) and a defect-rich sample (top). Lines calibrated to the $\mathrm{Zn} 2 \mathrm{p}_{3 / 2}$ line at $1021.8 \mathrm{eV}$.

[SI1] Moulder, J.F., et al., Handbook of X-ray Photoelectron Spectroscopy. $2^{\text {nd }}$ ed. 1992, Eden Prairie: Perkin Elmer Corporation. 